\title{
1 Enhanced properties of graphene/fly ash geopolymeric composite cement
}

2

3

4 5

6 | ${ }^{2}$ Agilent Technologies, -EH12 9DJ, UK

$7 \quad{ }^{3}$ Department of Pure and Applied Chemistry, University of Strathclyde, G4 0NG, UK

\section{Abstract}

This paper reports for the first time the incorporation of in-situ reduced graphene oxide (rGO) into geopolymers. The resulting rGO-geopolymeric composites are easy to manufacture and exhibit excellent mechanical properties. Geopolymers with graphene oxide (GO) concents of $0.00,0.10,0.35$ and $0.50 \%$ by weight were fabricated. The functional groups, morphology, void filling mechanisms and mechanical properties of the composites were determined. The Fourier transform infrared (FTIR) spectra revealed that the alkaline solution reduced the hydroxyl/carbonyl groups of GO by deoxygenation and/or dehydration. Concomitantly, the spectral absorbance related to silica type cross-linking increased in the spectra. The scanning electron microscope (SEM) micrographs indicated that rGO altered the morphology of geopolymers from a porous nature to a substantially pore filled morphology with increased mechanical properties. The flexural tests showed that 0.35 -wt $\%$ rGO produced the highest flexural strength, Young's modulus and flexural toughness and they were increased by $134 \%$, $376 \%$ and $56 \%$, respectively.

Keywords: C. Mechanical Properties, D. Alkali Activated Cement, E. Composite, D, Reinforcement.

*Corresponding author: m.bensalem.saafi@strath.ac.uk, Tel: 44 (0) 1415484569

\section{Introduction}

In recent years, considerable research has been aimed at the development of fly ash based geopolymers. This is driven by the need to reduce or complement the ordinary Portland 
cement (OPC) consumption in the construction industry. OPC is major contributor to greenhouse gases when compared to geopolymers. Geopolymers in general emit less green-house gases due to their lower calcium carbonate-based raw materials and production temperature. Geopolymers are inorganic polymers synthesized via a chemical reaction between a highly alkaline solution and the $\mathrm{Si}-\mathrm{Al}$ minerals present in the fly ash. This results in a 3-D polymeric network consisting of Si-O-Al-O bonds with the formula of $\mathrm{M}_{n}\left[-\left(\mathrm{SiO}_{2}\right)_{z}-\mathrm{AlO}_{2}\right] . \mathrm{wH}_{2} \mathrm{O}$ where $M$ is an alkaline element, $n$ is the degree of polymerization, $z$ is a value between 1 and 32, and $w$ is the hydration extent, which is a function of the type and amount of the alkaline solution used [1]. The most commonly used alkaline solution is a mixture of sodium silicate $\left(\mathrm{Na}_{2} \mathrm{SiO}_{3}\right)$ and sodium hydroxide $(\mathrm{NaOH})$ with a $\mathrm{Na}_{2} \mathrm{SiO}_{3} / \mathrm{NaOH}$ ratio between 1.5 and 3 [2]. The processed type F fly ash based geopolymers exhibit mechanical properties similar to those of OPC but with better performance under severe environmental conditions. For example, it has been reported that geopolymers exhibit excellent resistance to acid and sulfate attack when compared to OPC due to the lower calcium content of the fly ash [3-5]. Fly ash based geopolymers are also fire resistant binders. According to Pan el al. [6], geopolymers are inherently fire resistant due their polymeric-silicon-oxygen-aluminum framework. Pan et al. [6] and Duxson et al. [7] have shown that geopolymers can sustain high temperatures (up to $800^{\circ} \mathrm{C}$ ) with little gel structural degradation.

OPC and geopolymers are typically brittle and characterized by low tensile strength and fracture toughness. To combat this, OPC and geopolymers are often reinforced with micro and nano fibers. For example, fibers such as steel, polypropylene (PP), polyvinyl chloride

51 (PVC) and basalt fibers have been found to be particularly effective in controlling crack 52 propagation and enhancing the flexural strength and the fracture energy of geopolymers [8].

53 These enhanced properties were mainly attributed to the fiber bridging effect during both 54 micro and macro cracking of the geopolymeric matrix [8]. The mechanical interlocking at the 
fiber-matrix interface and chemical bonding between the fiber and the matrix both play a role in strengthening and toughening of the geopolymeric matrix [9].

Recently, carbon nanotubes (CNTs) were adopted as a reinforcement for geopolymers. The unique properties such as high elastic modulus and tensile strength and high aspect ratio make CNTs an ideal candidate for reinforcement. Mackenzie and Bolton [10] investigated the tensile strength of potassium-based aluminosilicate (clay) geopolymers containing single walled carbon nanotubes (SWCNTs) at concentrations of $0.20,0.25$ and 0.35 -wt $\%$. The tensile strength results were inconsistent. The tensile strength decreased, and then increased before it began to decrease again. Saafi et al. [11] studied the multifunctional properties of geopolymers containing multiwalled carbon nanotubes (MWCNTs). Their experimental results indicated that the incorporation of MWCNTs up to 0.5 -wt $\%$ enhanced the flexural strength, the Young's modulus, the flexural toughness and the fracture energy of geopolymers. This improvement was due to a variety of CNT strengthening and toughening mechanisms, including high resistance to crack coalescence, crack deflection at the CNT/matrix interface, inducing and bridging of multiple cracks and CNT pullout on the fractured surfaces [12].

A non-aggregated dispersion of CNTs in aqueous liquid media is a prerequisite for their use as reinforcing fillers in cement and geopolymer based composites. However, dispersion of CNTs in water is highly challenging as van der Waals forces between the CNTs create bundles and agglomerates. For CNTs, this phenomenon reduces the workability and mechanical properties of composites [13, 14]. Graphene offers many benefits over CNTs, including higher surface area (due to its 2-dimensional structure) and strong mechanical interaction with the hosting matrix resulting from the wrinkling [15]. However, graphene sheets exhibit very low dispersibility in polar liquids due to their high surface area and surface 
energy and, as a result, they agglomerate and stick to each other, thereby reducing their reinforcement effects when agglomerated [16].

Graphene oxide (GO), the oxidized form of graphite has been considered as a precursor for bulk-scale production of low-cost graphene-based materials [17]. GO sheets contain a large concentration of hydroxyl, epoxide, carboxyl and carbonyl functional groups [18]. These functional groups are compatible with water and therefore the GO is highly dispersible in polar liquids [19]. GO-based fillers were incorporated into various plastic and organic composites [20, 21]. The improved mechanical properties of these composites were attributed to the high specific surface area and excellent mechanical properties of GO sheets [21].

In view of these outstanding properties, the integration of graphene into geopolymers can significantly improve their properties and provide them with self-sensing capabilities. The objective of this paper is to investigate the mechanical properties, chemical functional group changes and morphological changes of geopolymers containing reduced GO (rGO) sheets at a variety of loadings. The properties discussed herein are the morphology characteristics, the flexural strength, the Young's modulus, the flexural toughness and the void and pore filling mechanisms together with chemical changes associated with the alkaline reduction of GO.

\section{Experimental program}

\subsection{Materials}

Class F fly ash was used to process the rGO-geopolymeric composites. The chemical composition of the fly ash is given in Table 1. Based on the size distribution tests conducted by the supplier, $70 \%$ by weight of the total type F fly ash spherical particles were between 0.2 and $5 \mu \mathrm{m}$ in diameter.

Hydrophilic and oxygenated $1.1 \mathrm{~nm}$ thick pristine GO sheets $(0.5-5 \mu \mathrm{m}$ with purity higher than $90 \%$, supplied by Supermarket ${ }^{\circledR}$ ) were employed in this study. The required GO content was dispersed in deionized water by using a 100W Cell Disruptor for 1.5 hours. The plain 
104 geopolymeric matrix had a bulk of density of $2.0 \mathrm{~g} / \mathrm{cm}^{3}$ and composed of $72-w t \%$ fly ash, 20105 wt $\%$ of sodium silicate $\left(\mathrm{Na}_{2} \mathrm{SiO}_{3}\right.$ with $29.4 \% \mathrm{SiO}_{2}, 14.7 \% \mathrm{NaO}_{2}$ and $\left.59.9 \% \mathrm{H}_{2} \mathrm{O}\right)$ and 8 -wt\% 106 of $10 \mathrm{M}$ sodium hydroxide $(\mathrm{NaOH})$. The $\left(\mathrm{Na}_{2} \mathrm{SiO}_{3}+\mathrm{NaOH}\right)$ to fly ash ratio was 0.39 .

\subsection{Fabrication of rGO-geopolymeric composites}

108 To chemically reduce the GO sheets during mixing and curing, the dispersed pristine GO 109 sheets were first added to $100 \mathrm{~g}$ of $\mathrm{NaOH}$ solution (10M) and mildly sonicated for 1 hour.

110 The stable and heterogeneous mixture was then mixed with the fly ash and the left over 111 chemicals $\left(\mathrm{Na}_{2} \mathrm{SiO}_{3}+\mathrm{NaOH}\right)$ for 1 minute. Subsequently, the mix was subjected to 112 sonication for 3 minutes prior to casting the beams. Geopolymeric beams (50 mm x $50 \mathrm{~mm} \mathrm{x}$ $113350 \mathrm{~mm})$ containing different concentrations of rGO $(0.00,0.10,0.35$ and 0.50 -wt $\%)$ were 114 prepared. The molded geopolymeric beams were first cured at a room temperature of $25^{\circ} \mathrm{C}$ for 1152 hours and then placed in an oven for 24 hours at constant temperature of $60^{\circ} \mathrm{C}$.

116 2.3. Morphology and chemical characterization

117 The morphology of the rGO-geopolymeric composites and the rGO sheets were examined 118 with a scanning electron microscope (SEM). SEM observations were also performed on the 119 rGO-geopolymeric suspensions in order to identify their morphology during processing. An 120 Agilent Technologies Exoscan 4100 Fourier transform mid-infrared spectrometer, with 121 diffuse sample interface, was used to collect infrared diffuse spectra. The instrumental 122 conditions for spectral collection were 128 scans at a resolution of $8 \mathrm{~cm}^{-1}$. The spectral 123 changes both in terms of size and position were used to identify the processes and chemical 124 changes in the pristine GO sheets and geopolymeric composites. In addition, the 125 geopolymeric gels and the rGO sheets were also studied with particular attention paid to the 126 chemical bonding and functional groups present. 
130 In total, 10 geopolymeric beams per rGO content were prepared for the mechanical 131 characterization. The beams had a clear span of $210 \mathrm{~mm}$ and a distance between the two 132 loading contacts of $70 \mathrm{~mm}$. The beams were subjected to four-point bending tests to 133 determine the mechanical properties; namely, flexural strength, Young's modulus and flexural 134 toughness. The four-point bending tests were conducted under displacement control with a 135 rate of $0.05 \mathrm{~mm} / \mathrm{min}$. During testing, load and deflection at the center were recorded continuously. The flexural strength $\left(\sigma_{f}\right)$ and the Young's modulus $(E)$ were calculated as:

$$
\begin{aligned}
& \sigma_{f}=\frac{3 P a}{b^{3}} \\
& E=m \frac{a\left(3 l^{2}-4 a^{2}\right)}{4 b^{4}}
\end{aligned}
$$

139 where $P$ is the maximum applied load, $l$ is the length of the beam between the supports, $a$ is

140 the distance between the support and the loading point, $b$ is the width and thickness of the 141 beam and $m$ is the slope of the tangent to the straight-line portion of the load-deflection curve. 142 The flexural toughness of the beams is the total area under the stress-strain curve obtained 143 from Eqs. 1 and 3, where Eq. 3 is given by:

$$
\varepsilon=\frac{12 b \Delta}{3 b^{2}-4 a^{2}}
$$

145 where $\varepsilon$ is the tensile strain and $\Delta$ is the displacement recorded by the LVDT.

\section{3. Results and discussion}

\subsection{FTIR analysis and chemical characterization}

148 Figure 1 depicts the FTIR spectrum of the fly ash, (black dashed line), pristine GO sheets

149 (yellow solid line), plain geopolymers (red dash-dotted line) and rGO-geopolymers with 0.35150 wt\% (blue dotted line). The FTIR spectrum of the fly ash is dominated by two overlapping 151 peaks corresponding to Si-O (doublet) and $\mathrm{Al}-\mathrm{O}$ functional groups or bonds in the range of 
152800 to $1200 \mathrm{~cm}^{-1}$. These groups are clearly observed in the spectra as shown in Fig. 2. The

153 Si-O and Al-O overlapping (negative) restrahlen peaks represent the main mineral content of

154 the fly ash (see Table 1 ) and are much greater than the $\mathrm{C}-\mathrm{H}$ stretching modes that are the two

155 downward peaks in the spectral region of $3000-2850 \mathrm{~cm}^{-1}$. The organic content $(\mathrm{C}-\mathrm{H})$ of the

156 fly ash is much smaller than the mineral content (Si-O and Al-O) in good agreement with

157 Table 1. The restrahlen peak absorbances at $\sim 1800-1700 \mathrm{~cm}^{-1}$ are the result of the presence of

158 other organic functional groups in the fly ash, namely carbonyl type species. Finally, a

159 variety of hydrogen bonded -OH functional groups derived from $\mathrm{Al}-\mathrm{OH}, \mathrm{Si}-\mathrm{OH}$ and $\mathrm{C}-\mathrm{OH}$

160 exist in the dried fly ash as evidenced by the complexity of the peak shape in -OH functional

161 group (3000-3700 $\left.\mathrm{cm}^{-1}\right)$.

162 From Fig. 1, it can be seen that the pristine GO sheets contain high concentrations of

163 hydroxyl (at 3000-3700 $\mathrm{cm}^{-1}$ and $\left.\sim 1600 \mathrm{~cm}^{-1}\right)$ and carbonyl $\left(\sim 1700 \mathrm{~cm}^{-1}\right)$ functional groups.

164 The FTIR spectrum of the unreduced GO sheets also displays the existence of

165 methyl/methylene $\left(\mathrm{CH}_{2} / \mathrm{CH}_{3}\right)$ stretches between 3000 and $2800 \mathrm{~cm}^{1}$. These groups are

166 concentrated at the edges of the GO sheets.

167 For both geopolymers (red line or blue line in Fig. 1 - with or without GO), the alkaline

168 activator $\left(\mathrm{NaOH}+\mathrm{Na}_{2} \mathrm{SiO}_{3}\right)$ changed the fly ash hydroxyl spectral absorbance peak shape

169 from a complex distribution to a near homogeneous hydroxyl functional group. These

170 chemical changes are due to the loss of the peak as a consequence of bond destruction. Figure

1711 indicates a distinct shape change for the $-\mathrm{OH}$ from the base fly ash to the geopolymer. It

172 also shows that the alkaline activator changed the distribution of the Al-O/Si-O regions at

$173800-1200 \mathrm{~cm}^{-1}$ for both geopolymers. The addition of sodium silicate increased the relative

174 concentration of $\mathrm{Si}-\mathrm{O}$ in the geopolymeric matrix. As expected due to the presence of rGO,

175 the rGO geopolymers exhibited higher organic contents at $\sim 1500 \mathrm{~cm}^{-1}$ as compared to the

176 plain geopolymers. These negative/derivative peak shapes are caused by concomitant 
177 changes in the refractive index with the absorbance changes as shown by the downward negative peaks in the indicated region in figure 1 . This is very common in materials that contain high silicate content or similar and/or contain highly scatteruing components such as flyash or graphene oxide.. . From the FTIR spectrum of the rGO-geopolymetric matrix, it 181 can be seen that the GO has undergone chemical reduction of the hydroxyl and carbonyl 182 functional groups, whereas the unreactive $\mathrm{C}-\mathrm{H}$ peaks at $1500 \mathrm{~cm}^{-1}$ remained largely unchanged due to their inert nature.

Figure 2 shows the FTIR spectra between $2000-650 \mathrm{~cm}^{-1}$ of both the plain and the rGO reinforced geopolymers. As shown in this figure, the presence of the rGO in the geopolymeric matrix increased the moderately absorbing band at $\sim 1425 \mathrm{~cm}^{-1}$, this can be assigned to a $\mathrm{C}-\mathrm{H}$ vibration. In addition, the Si-O bonds increased the absorbance at 1000 $1200 \mathrm{~cm}^{-1}$ as a direct result of the chemical reaction of the sodium silicate with the matrix components creating new $\mathrm{Si}-\mathrm{O}_{2}$ based cross-linking with fly ash or rGO. The change in absorbance is marked large considering the rGO addition was a mere $0.35 \mathrm{wt} \%$

Figure 3 further confirms that the pristine GO sheets have been reduced during the 192 processing of the geopolymers. This figure compares the FTIR spectra of the isolated 193 unreduced/pristine GO sheets with the difference spectra of the geopolymer with and without 194 the incorporation of $0.35 \mathrm{wt} \%$ GO. The dotted blue line is the difference between each single point of the spectra presented in Fig. 3 for the full spectral region. As can be seen from this figure, there is a clear attenuation of hydroxyl and carbonyl functionalities between 3000 and $3750 \mathrm{~cm}^{-1}$ and, between 1650 and $1800 \mathrm{~cm}^{-1}$, respectively. High attenuation of the hydroxyl 198 and carbonyl groups inidicating reduction of GO by the alkali $\mathrm{NaOH}[22,23]$ as shown in the 199 difference spectra. The non-reducible functional groups of the GO are still present in the difference spectra at $3000-2850 \mathrm{~cm}^{-1}$ and at $1200-1500 \mathrm{~cm}^{-1}$, these are the unreactive $\mathrm{C}-\mathrm{H}$

201 type bonds. Previous studies have shown that during processing with $\mathrm{NaOH}$ or strong alkali, 
202 the GO sheets undergo deoxygenation and the number of carbonyl and hydroxyl groups are 203 then reduced. This leads to the formation of highly reducedGO sheets (rGO) with mechanical 204 and electrical properties superior to those of pristine GO sheets [22, 23]. The authors suggest 205 that the GO incorporated into the geopolymer actually contains the in-situ reduced-GO cross206 linked graphene based material within the geopolymer matrix thereby increasing mechanical 207 and electrical properties. Additionally greatly lowering porosity.

208 The mechanical properties of the rGO-geopolymeric composites are highly dependent on 209 the physical and chemical interactions between the rGO and the matrix. These interactions 210 include both mechanical and chemical covalent bonding. The mechanical interaction is due to 211 the mechanical interlocking between the textured (wrinkled) morphology of the rGO sheets 212 and the matrix. The Si-O covalent bond absorbance augmentation is likely to be the cross213 linking bridging between the fly ash and the rGO sheets. The authors suggest that the in-situ 214 cross-linked particles in the form of $[-\mathrm{Si}-\mathrm{O}-]_{\mathrm{x}}[\mathrm{rGO}]_{\mathrm{y}}[-\mathrm{O}-\mathrm{Si}-]_{\mathrm{z}}$ (with $\mathrm{x} \geq 1, \mathrm{y} \geq$ and $\mathrm{z} \geq 0$ ) is 215 formed in the rGO-geopolymeric matrices. The silicon has the ability to further bond to the 216 fly ash or rGO, this creates a diverse particle size, shape and morphologies enabling virtually 217 any pore or void to be filled. Moreover unreacted hydroxyl groups on the GO or fly ash can 218 undergo further cross-linking to become larger crack filling and bridging particles.

\section{3.2. Morphology}

220 The morphology of the fly ash is well known and is a wide distribution of mostly spherical 221 particles that encompasses the submicron to the micron range. These particles are the 222 dominant base for both types of geopolymers and are highly siliceous. Figure 4a shows the 223 SEM micrograph of the rGO sheets, clearly there is a highly textured morphology enabling 224 the rGO to morph around complex shapes and interact mechanically. The chemical alkaline 225 reduction of GO to rGO (reduced form) removes the oxygen rich functional groups as well as 226 causing the high degree of wrinkling and folding [24]. Wrinkles have a positive effect on the 
227 mechanical properties of rGO reinforced geopolymers, as they tend to improve the 228 interlocking mechanism within the matrix [25]. Figures 4b, 4c and 4d show the morphology 229 of the geopolymeric suspensions containing $0.35-w t \%$ rGO. In Fig. 4b, the sub-micron fly 230 ash spheres are randomly deposited on the rGO sheets. The rGO sheets exhibited random 231 holes and tearing. From Fig. 4b, it can be seen that the size the submicron fly ash spheres 232 matches the size of the holes, suggesting that some of the particles pierced the rGO sheets 233 during processing, resulting in random holes. Fig. 4c shows the fly ash particles covered 234 with thin rGO sheets, forming hybrid clusters. This can be attributed to the effect of cross235 linking and functionalization on the surface area of the rGO sheets and the fly ash particles $236[26,27]$. The exchange between the two materials typically occurs through electric induction 237 (also known as polarization) causing the rGO sheets to adsorb onto the fly ash particles. The 238 strain induced by the largest fly ash particles also caused the folding of the flexible rGO 239 sheets around the largest fly ash particles, producing shapes like a "mushroom" as shown in 240 Figs. 4c and 4d. One possible interpretation for this observation is that the rGO sheets 241 inherently contain both crystalline and amorphous regions. The amorphous region is less 242 stable, more soluble and relatively disordered thus becomes more amenable to deform when 243 the fly ash particles push against it.

$244 \quad$ Figures $4 \mathrm{c}$ and $4 \mathrm{~d}$ also show that the pores and voids were substantially filled and bridged 245 at $0.35-w t \%$, partially due to the formation of the cross-linked particles. The pore filling with 246 the malleable rGO sheets also reduced the porosity and presence of voids. Additionally, the 247 small scraps of rGO sheets that were moved by the fly ash particles also filled and bridged the 248 voids and hollow spaces in the matrix as depicted in Fig. 5.

\section{3.3. Mechanical characterization}

250 Figure 6 shows the load-deflection responses of the geopolymeric beams. The beams were 251 initially preloaded up to a deflection of $0.2 \mathrm{~mm}$ to ensure good contact with the load and 
support points. The load-deflections results indicated the significant increase in stiffness and

253 load-carrying capacity of the beams due to the addition of rGO sheets. This is attributed to 254 the stiffness and surface area of the rGO sheets. The wrinkled texture of the rGO sheets also 255 played a positive role in the load transfer between the rGO sheets and the geopolymeric 256 matrix, as it tends to enhance the mechanical interlocking coupled with chemical cross257 linking type bonding.

The deflection at failure decreased as the rGO sheet content increased. This can be explained as follows (see Fig. 7): at low rGO sheet contents, the sheets are generally separated and randomly dispersed within the matrix with a slight negative effect on the mechanical deformation. At medium rGO contents, the sheets are joined together with some overlapping each other, producing stiff plates rigidly bonded to the matrix. In this case, the

263 matrix is restrained from movement and as a result the deflection is reduced. Severe 264 restacking of sheets occurs at high rGO sheet contents due to van-der-Waals forces (van-der265 Waals forces from $\mathrm{NaOH}$-induced attenuation of hydroxyl groups) where the sheets are 266 stacked on top of each other to form rigid laminates. This further restricts the movement of 267 the matrix, causing the beams to fail in a brittle manner. This behavior has also been found in 268 other graphene-based polymer composites [28, 29].

269 The average mechanical properties are given in Fig. 8. A noticeable flexural strength gain 270 of $49 \%, 130 \%$ and $134 \%$ was achieved for beams with rGO sheet concentrations of $0.10,0.35$ 271 and 0.50-wt\%, respectively. A significant increase in stiffness was also obtained. The 272 increase was about $107 \%, 365 \%$ and $376 \%$ for rGO contents of $0.10,0.35$ and 0.50 -wt $\%$, 273 respectively. The flexural toughness was improved by $12 \%, 56 \%$ and $48 \%$ for rGO contents 274 of $0.10,0.35$ and 50 -wt $\%$, respectively. The geopolymers with 0.35 and 0.5 -wt $\%$ rGO 275 exhibited somewhat similar mechanical properties, indicating a mechanical percolation 276 threshold was achieved at 0.35-wt\%. These results are in line with previous studies on 
graphene composites [30, 31]. These studies have shown that graphene sheets can enhance the mechanical properties of composites at significantly lower graphene concentrations in comparison to CNTs. For example, $0.125-w t \%$ of graphene increased the tensile strength and the Young's modulus of polymers by $45 \%$ and $50 \%$, respectively, whereas, $1-\mathrm{wt} \%$ of CNTs increased the tensile strength and the Young's modulus of polymers by $15 \%$ and $30 \%$, 282 respectively [30].

\subsection{Toughening and load transfer mechanisms}

284 The rGO morphology and the shear lag model can be used to quantify the load transfer 285 mechanism in the rGO-geopolymeric composites. The relationship between the strain $\varepsilon_{p}$ in 286 the rGO sheet and the geopolymeric matrix strain $\varepsilon_{m}$, can be written as [32]:

$$
\varepsilon_{p}=\varepsilon_{m}\left[1-\frac{\cosh \left(n s \frac{x}{l}\right)}{\cosh (n s / l)}\right]
$$

$$
n=\sqrt{\frac{2 G_{m}}{E_{p}} \frac{t}{T}}
$$

289 where $G_{m}$ is the shear modulus of the matrix, $E_{p}$ is the Young's modulus of the rGO sheet, $l$ is 290 the length of the rGO sheet in the $x$ direction, $t$ is the thickness of the rGO sheet, $T$ is the total 291 thickness of the matrix and $s$ is the aspect ratio of the rGO sheet $(l / t)$ in the $x$ direction. In 292 Eq. (4), the parameter $n$ is an effective measure of the interfacial stress transfer efficiency and 293 the product ns depending on both the morphology of the rGO sheet and the degree of 294 interaction with the hosting geopolymeric matrix [32].

295 The morphology of the wrinkled rGO sheet shown in Fig. 6a can be characterized by the 296 wavelength $\lambda$ and the amplitude $A$ of the wrinkles as [33]:

$$
\lambda^{4}=\frac{4 \pi^{2} v(t l)^{2}}{3\left(1-v^{2}\right) \varepsilon}
$$




$$
A^{2}=\left[\frac{16 \varepsilon v}{3 \pi^{2}\left(1-v^{2}\right)}\right]^{1 / 2} t l
$$

where $v$ is the Poisson's ratio of the rGO sheet and $\varepsilon$ is the compressive strain in the rGO sheet from the exfoliation process.

The shear stress between the rGO sheet and the geopolymeric matrix is given by [32]:

$$
\tau=n E_{p} \varepsilon_{m} \frac{\sinh \left(n s \frac{x}{l}\right)}{\cosh (n s / 2)}
$$

As can be seen from Eqs. (4), (5), (6) and (7), the high aspect ratio $s=1 / t$, the Young's modulus $E_{p}$ and the morphology of the rGO sheet are the main key factors that significantly contributed to the improved mechanical properties of rGO reinforced geopolymers composites .

The toughening mechanism in graphene composites is not well understood and research on this topic is limited. This can be attributed to the difficulty of identifying crack pinning or crack bridging by the graphene sheets using traditional analysis tools such as SEM [34]. Rafiee et al. [31] have shown that the toughening mechanism in composites reinforced with graphene is different from that reinforced with CNTs. In CNTs, the toughness is dominated by the crack-bridging mechanism where the energy is dissipated by the frictional pullout of the bridging CNTs from the matrix. However, in graphene, the toughening mechanism is crack deflection. In this case, microcracks are deflected and twisted when they run into a rigid graphene sheet. Rafiee et al. [31] reported that this mechanism increases the total fracture surface leading to greater energy absorption. Although further validation studies are needed to identify the toughening mechanism, the experimental results presented herein suggest that crack deflection may have occurred in the rGO-geopolymeric composites and it is reflected in their high Young’s modulus and flexural toughness (see Fig. 8).

\section{Conclusions}


321 New rGO-geopolymeric composites with enhanced properties were successfully produced 322 using the same mixing method used to make OPC. The interaction of the GO sheets with the 323 alkaline solution used to process the geopolymeric composites yielded highly reduced and 324 cross-linked GO sheets. The addition of these rGO sheets into geopolymers at very low 325 contents simultaneously improved the mechanical properties and reduced the overall porosity 326 of geopolymers. The malleable rGO sheets and the small scraps of rGO sheets that were 327 moved by the fly ash particles filled the voids and hollow spaces in the matrix. The 328 incorporation of rGO sheets improved the mechanical properties of the geopolymeric 329 composites as a result of their 2-dimensional structure and good chemical bonding with the 330 matrix. The rGO concentration of $0.35-\mathrm{wt} \%$ yielded the highest mechanical properties. At 331 this concentration, the flexural strength and Young's modulus increased by $134 \%$ and 376\%, 332 respectively. A moderate increase in toughness (as much as 56\%) was obtained due to the 333 restacking of the rGO sheets and the formation of stiff hybrid of rGO-fly ash fillers within the

334 matrix. The rGO-geopolymeric composites can be an environmental friendly and economical 335 alternative to OPC due to their low green-house gas emissions and improved mechanical 336 properties. The in-situ reduction of GO makes geopolymers ideal candidates for high 337 performance and (potentially) self-sensing structural materials for various applications such as 338 bridges, roadways and smart structures with inherent increased durability due their near pore339 free morphology.

\section{$340 \quad$ References}

341 [1] Sakulich AR. Reinforced geopolymer composites for enhanced material greenness and 342 durability. Sustainable Cities and Society 2011; 1:195-210.

343 [2] Hardjito D. Studies on fly ash-based geopolymer concrete. PhD thesis 2005, Curtin $344 \quad$ University of Technology, Australia. 
345 [3] Bakharev T. Resistance of geopolymer materials to acid attack. Cement and Concrete $346 \quad$ Research 2005; 35(5): 658-670.

347 [4] Bakharev T. Durability of geopolymer materials in sodium and magnesium sulfate 348 solutions. Cement and Concrete Research 2005; 35(6): 1233-1246.

349 [5] Shankar HS and Khadiranaikar RB. Performance of geopolymer concrete under severe 350 environmental conditions. International Journal of Civil and Structural Engineering 2012; $351 \quad 3(2): 396-407$

352 [6] Pan Z, Sanjayan JG and Collins F. Effect of transient creep on compressive strength of 353 geopolymer concrete for elevated temperature exposure. Cement and Concrete Research $354 \quad$ 2014; 56: 182-189.

355 [7] Duxson P, Lukey GC and van Deventer JSJ, Thermal evolution of metakaolin 356 geopolymers: part 1—physical evolution. Journal of Non-Crystalline Solids 2006; 352(52357 [8] Uddin F, Shaik A. Review of mechanical properties of short fibers reinforced geopolymer composites. Construction and Building Materials 2013; 43: 37-49.

359 [9] D.P. Dias DP, Thaumaturgo C. Fracture toughness of geopolymeric concretes reinforced with basalt fibres. Cement and Concrete Composites 2005, 27: 49-54

361 [10] Mackenzie KJD, Bolton MJ. "Electrical and mechanical properties of aluminosilicate inorganic polymer composites with carbon nanotubes. Journal of Material Sciences 2009; 44(11): 2851-2857.

364 [11] Saafi M, Andrew K, Tang PK, McGhon D, Taylor S, Rahman M, Yang S, Zhou X. 365 Multifunctional properties of carbon nanotube/fly geopolymeric nanocomposites. 366 Construction and Building Materials 2013; 49: 46-55.

367 [12] Xia Z, Riester L, W.A Curtin WA, Lia H, Sheldon BW, Liang J, Chang B, Xu JM. 368 Direct observation of toughening mechanisms in carbon nanotube ceramic matrix 369 composites. Acta Materialia 2004; 52 (4): 931-944. 
370 [13] Collins F, Lambert J, Duan WH. The influence of admixtures on the dispersion, workability, and strength of carbon nanotube-OPC paste mixtures. Cement and Concrete Composites 2012; 34(2): 201-207.

[14] Abu-Al-Rub RK, Tyson BM, Yazdanbakhsh A, Grasley, Z. Mechanical properties of nanocomposite cement incorporating surface-treated and untreated carbon nanotubes and carbon nanofibers. ASCE Journal of Nanomechanics and Micromechanics 2012; 2(1): 16.

[15] Porwal, H., Grasso S, Reece M. Review of graphene-ceramic matrix composites. Advances in Applied Ceramics 2013; doi 10.1179/1743676113Y.0000000095.

[16] Yang Y, William R, Xinyu, Huang X, Li X. Enhancing graphene reinforcing potential in composites by hydrogen passivation induced dispersion. Scientific Reports 2013; 3: 2086; doi: 10.1038/srep02086.

[17] Zhu Y, Murali S, Cai W, Li X, Won SJ, Potts, JR, Ruoff RS. Graphene and graphene Oxide: synthesis, properties and applications. Advanced Materials 2010; 22(35), 39063924.

[18] Stankovich S, Piner RD, Nguyen ST, Ruoff RS. Synthesis and exfoliation of isocyanatetreated graphene oxide nanoplatelets. Carbon 2006; 44(15) 3342-3347.

[19] Kim DH, Yun YS, Jin HJ. Difference of dispersion behavior between graphene oxide and oxidized carbon nanotubes in polar organic solvents. Current Applied Physics 2012; 12(3): 637-642.

[20] Kim H, Abdala AA, Macosko, CW. Graphene/polymer nanocomposites. Macromolecules 2010; 43(16): 6515-6530.

392 [21] Du J, Cheng HM. The Fabrication, properties and uses of graphene/polymer composites Macromol Chem Phy 2012; 213: 1060-1077. 
394 [22] Thomas H R, Valles C, Young RJ, Kinloch IA, Wilson NR, Rourke PJ. Identifying the 395 fluorescence of graphene oxide. Journal of Mater Chem C 2013, 1: 338-342.

396 [23] Fan X, Peng W, Li Y, Wang S, Zhang G, Zhang F. Deoxygenation of exfoliated graphite oxide under alkaline conditions: a green route to graphene preparation. Adv Mater 2008; 20: 4490-4493.

[24] Bai S, Shen X, Zhu G, Yuan A, Zhang J, Ji Z, Qiu D. The influence of wrinkling in 400 reduced graphene oxide on their adsorption and catalytic properties. Carbon 2013; 60:

[25] Galpaya D, Wang M, Yan C, Liu M, Motta N, Waclawik ER. (2013) Fabrication and 403 mechanical and thermal behaviour of graphene oxide/epoxy nanocomposites. Journal of Multifunctional Composites 2013, 1(2): 91-98.

[26] ] Hsu TC. Adsorption of an acid dye onto fly ash. Fuel 2008; 87:3040-3045.

[27] Willner MR. Metal removable by sodium graphene oxide. Master of Science in Environmental Engineering 2012, University of Notre Dame, Indiana.

[28] Li Z, Young RJ, Kinloch IA. Interfacial stress transfer in graphene oxide nanocomposites. ACS Appl Mater Interfaces 2013; 5: 456-463..

410 [29] Zhao X, Zhang Q, Chen D. Enhanced mechanical properties of graphene-based poly(vinyl alcohol) composites. Macromolecules 2010; 43: 2357-2363.

412 [30] Rafiee MA, Rafiee J, Srivastava I, Wang Z, Song H, Yu, ZZ, Koratkar N. Fracture and fatigue in graphene nanocomposites. Small 2010; 6(2), 179-183.

414 [31] Rafiee MA, Rafiee J, Srivastava I, Wang Z, Song H, Yu ZZ, Koratkar N. Enhanced mechanical properties of nanocomposites at low graphene content. ACS Nano 2009; 3(12): 3884-3890. 
417 [32] Gong L, Kinloch IA, Young RJ, Riaz I, Jalil R, Novoselov KS. Interfacial stress 418 transfer in a graphene monolayer nanocomposite. Advanced Materials 2010; 22(24): $419 \quad 2694-2697$.

420 [33] Tapasztó L, Dumitrica T, Jin-Kim S, Nemes-Incze P, Hwang C, Biró LP. Break-down of 421 continuum mechanics for nanometer-wavelength rippling of graphene. Nature Physics $422 \quad$ 2012; 8: 739-741.

423 [34] Graphene in composite materials: synthesis, characterization and applications. Edited by 424 Koratkar N, March 2003, DEStech Publications, Inc.

425

426 


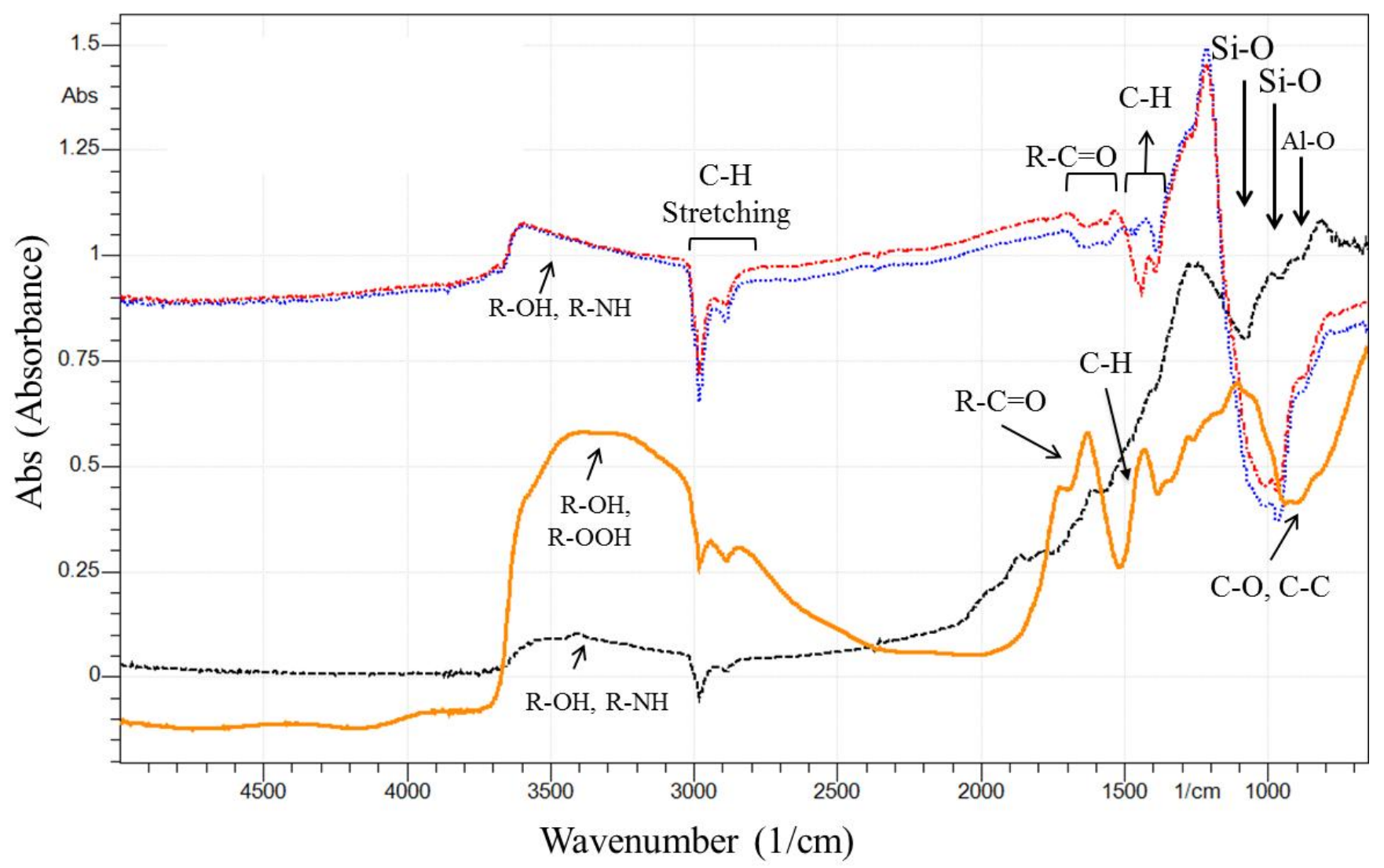

Fig. 1 - Diffuse FTIR spectra of fly ash (black line), un-reduced GO sheets (orange line), plain geopolymeric composites (red line) and rGO incorporated into the geopolymeric composites (blue line).

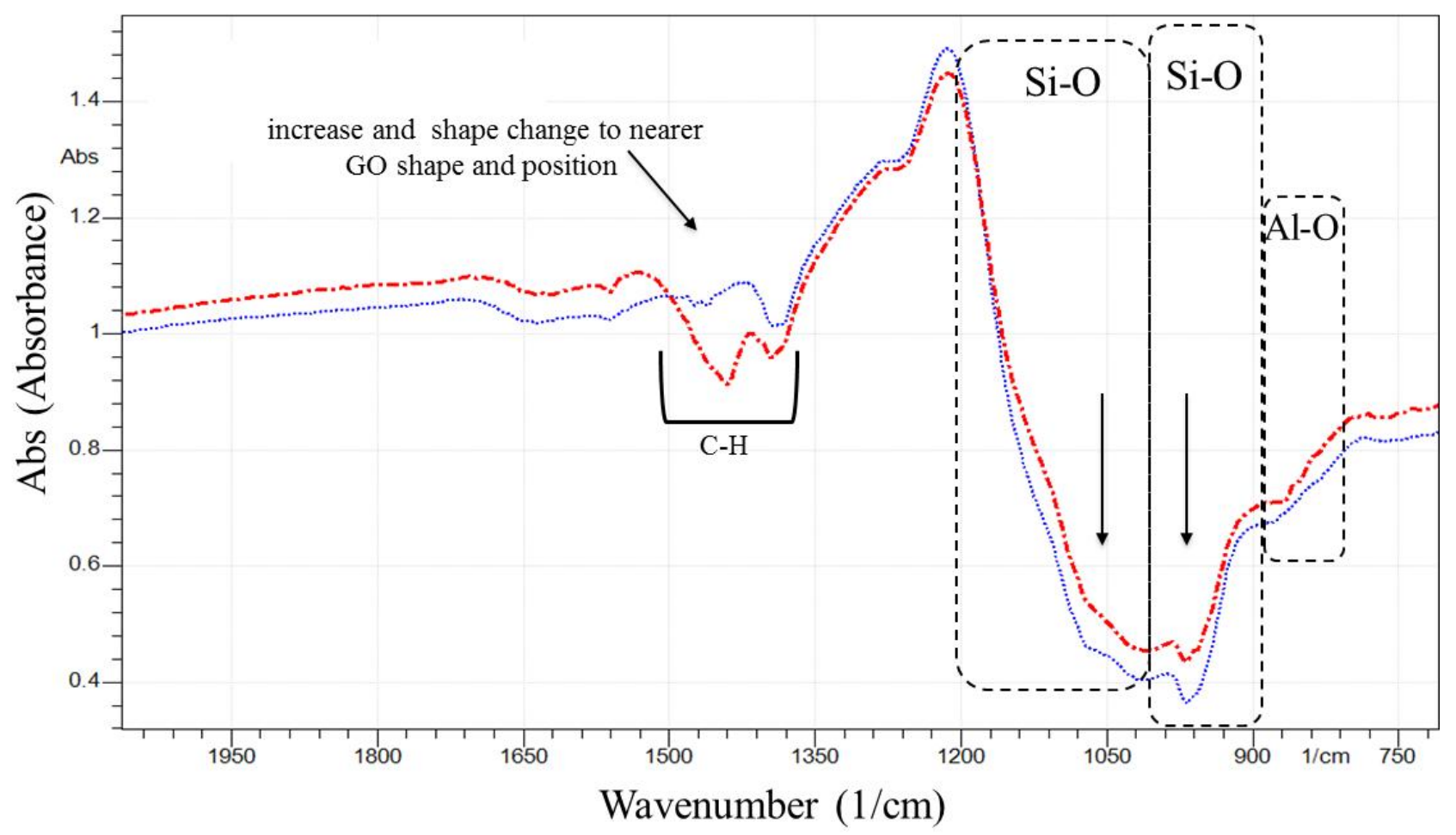

Fig.2- Diffuse FTIR spectra between 2000 and 650 1/cm of plain geopolymeric composites (red line) and rGO incorporated into the geopolymeric composites (blue line). 


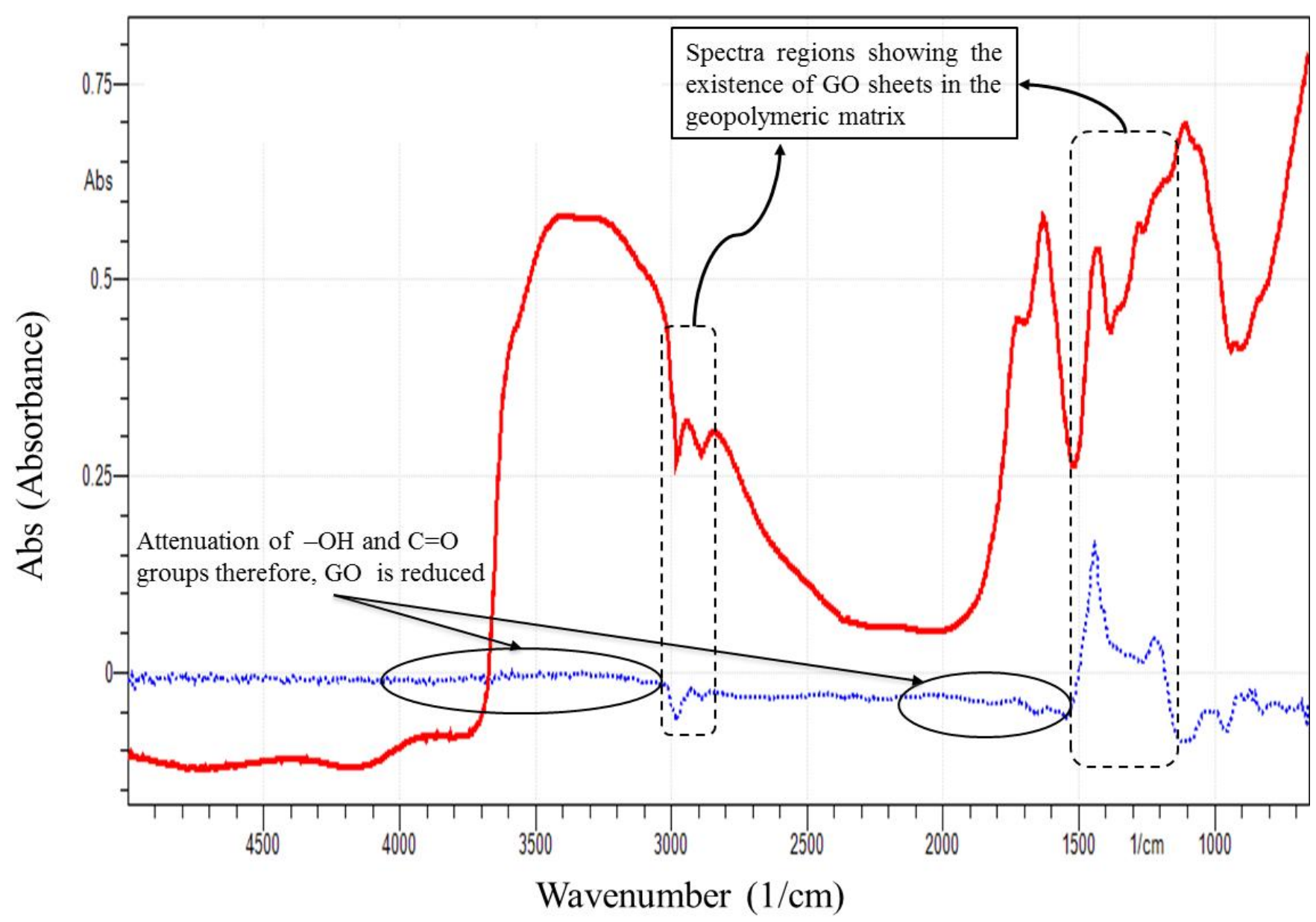

Fig. 3- Diffuse FTIR spectra of un-reduced GO (red line) in comparison to the difference spectra (blue line) of the geopolymer with and without rGO. 

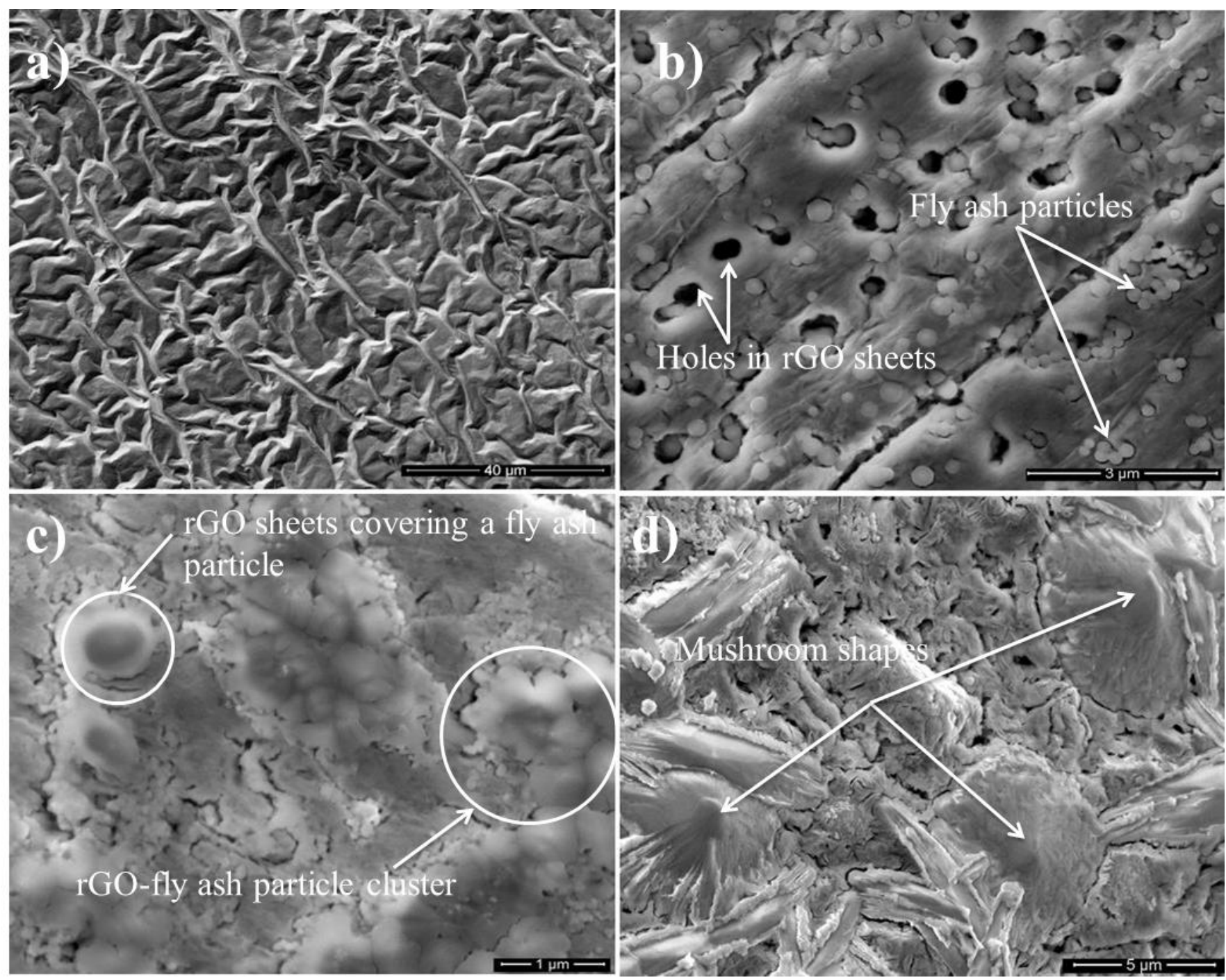

Fig.4 - SEM micrographs (a) morphology of rGO sheets (b) 0.35-wt\% GO sheets interaction with submicron fly ash, (c) 0.35-wt\% GO sheets coverinig submicron fly ash particles, (d) 0.35-wt\% GO sheets interaction with larger fly ash particles. 


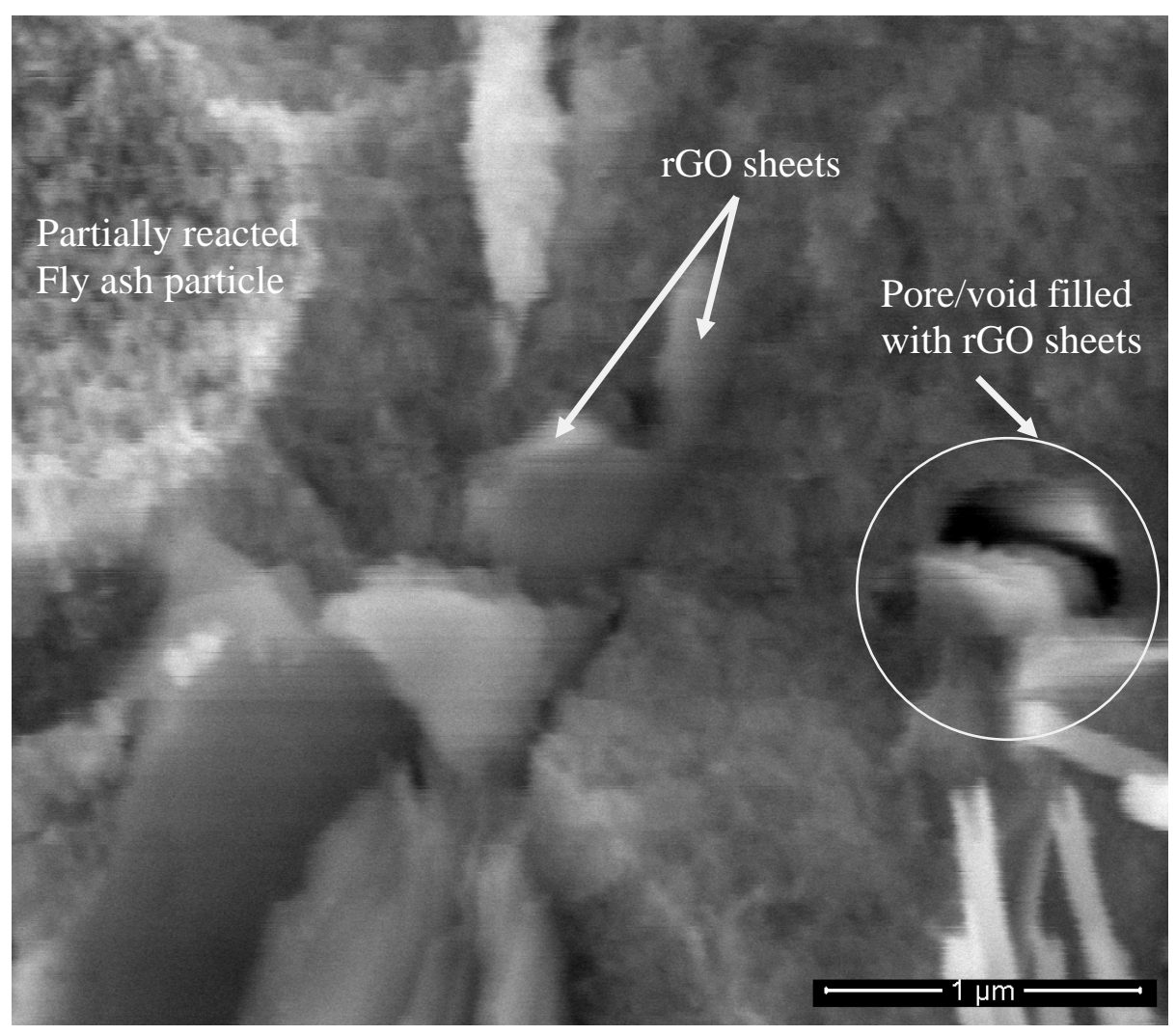

Fig. 5- SEM micrograph showing 0.5-wt\% rGO sheets filling pores and voids.

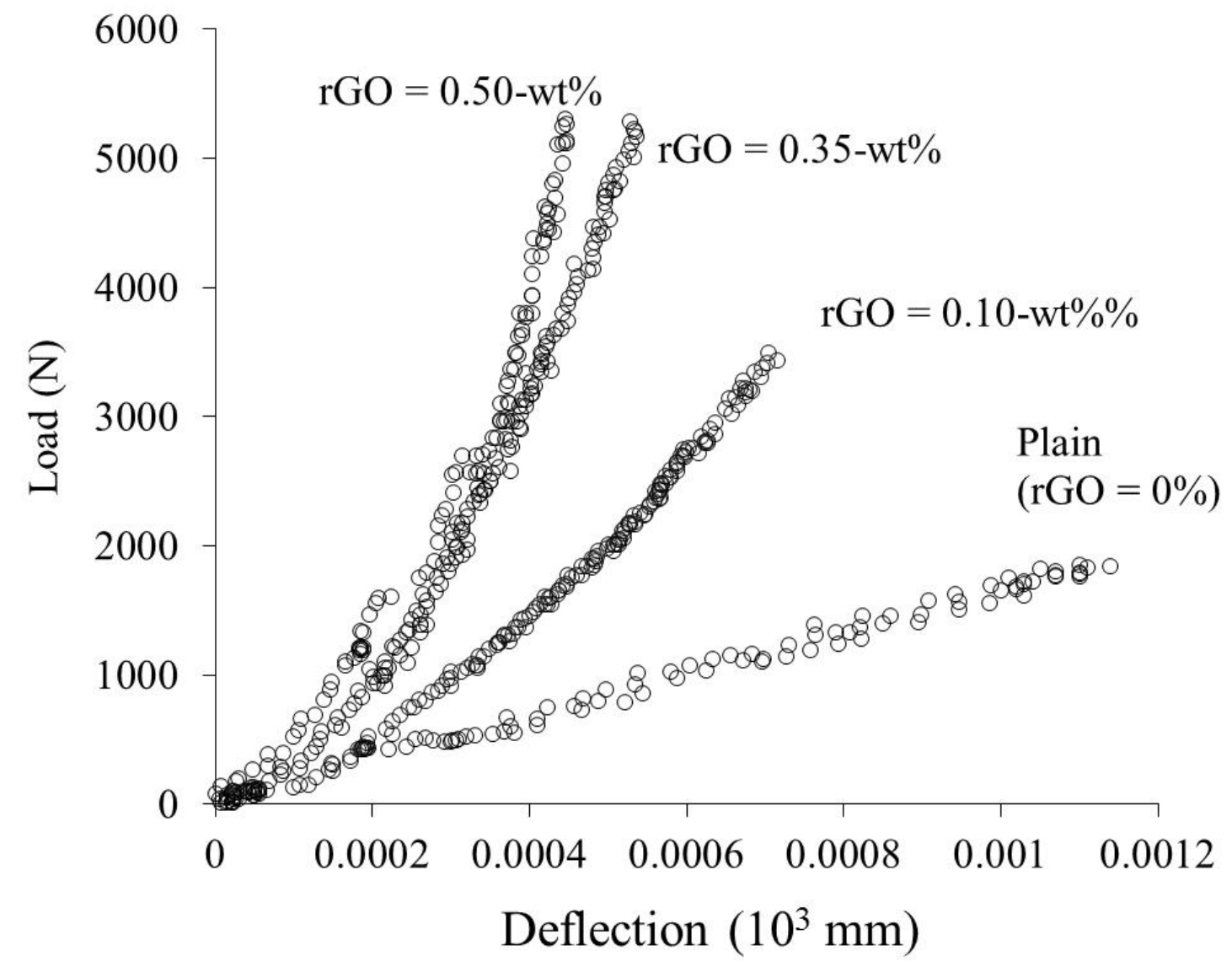

Fig.6-Load-deflection response of the rGO-geopolymeric composite beams. 


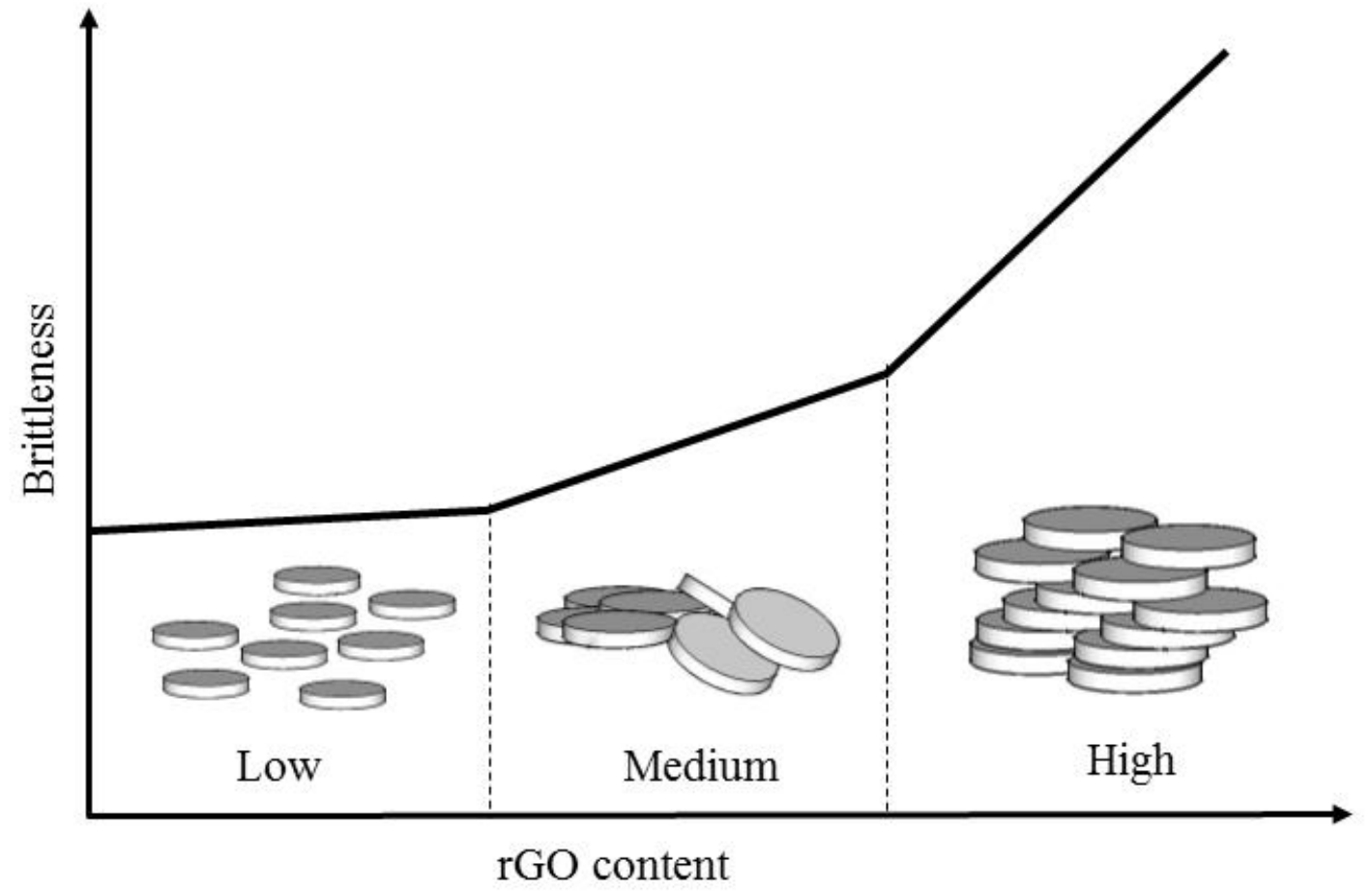

Fig. 7-Effect of rGO content on the brittleness of rGO-geopolymeric composites 

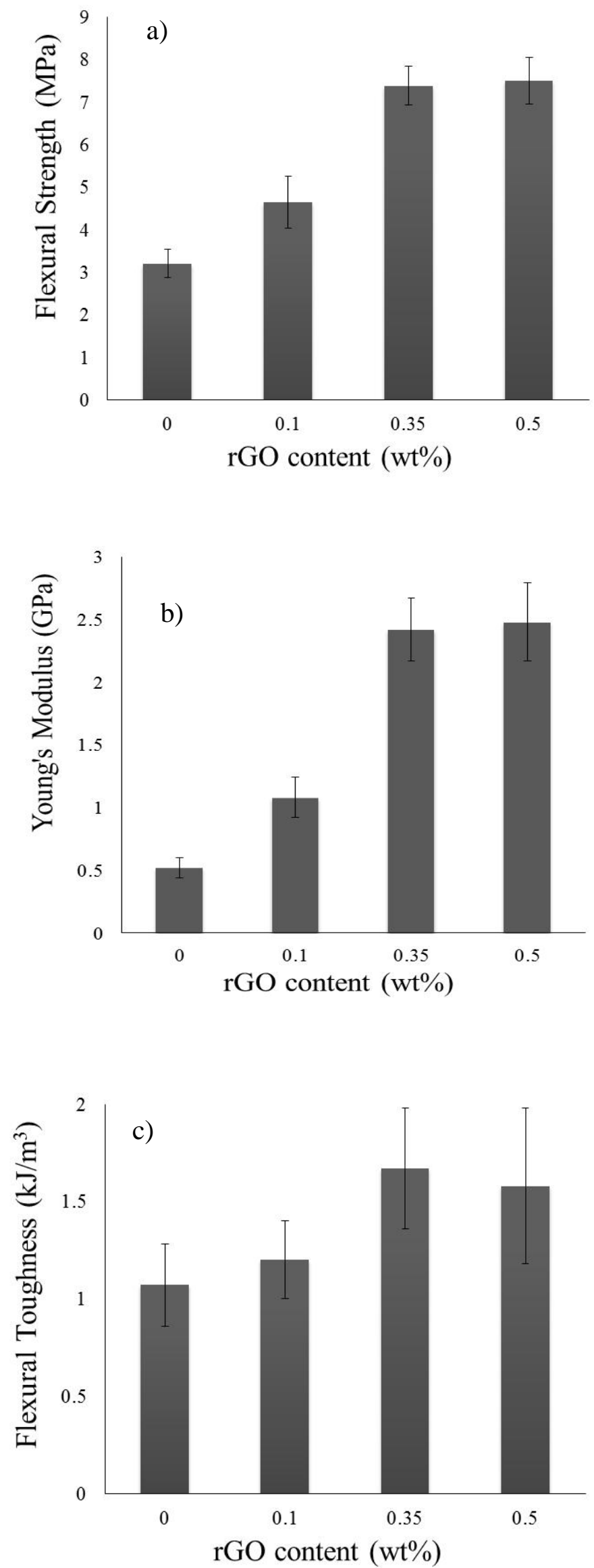

Fig.8- Mechanical properties of rGO-geopolymeric composites. a) flexural strength, b) Young's modulus, c) flexural toughness. 
Table 1. Main chemical composition of fly ash (wt\%) (as provided by the supplier)

\begin{tabular}{lr}
\hline Element & Weight \% \\
\hline Silicon dioxide, $\mathrm{SiO}_{2}$ & 53.50 \\
Aluminium oxide, $\mathrm{Al}_{2} \mathrm{O}_{3}$ & 34.30 \\
Iron oxide, $\mathrm{Fe}_{2} \mathrm{O}_{3}$ & 3.60 \\
Calcium oxide, $\mathrm{CaO}$ & 4.40 \\
Loss of Ignition & 2.00 \\
\hline
\end{tabular}

